RBEn 28 : 30-51, 1971،

\title{
ESTUDO COMPARATIVO DE RECENTES PESQUISAS COM A VACINA BCG POR VIA INTRADÉRMICA NO BRASIL - ANALOGIA DA CONTRIBUIÇÃO DA ENFERMEIRA
}

\author{
Ieda Barreira e Castro* \\ Jurema Aranha dos Santos** \\ Maria Alice Rodrigues de Lima** \\ Maria Juvanira Venâncios Trovonos **
}

$\mathrm{RBEn} / 04$

CASTRO, I.B. e colaboradores - Estudo comparativo de recentes pesquisas com a vacina BCG por via intradérmica no Brasil - Análise da contribuição da Enfermeira. Rev. Bras. Enf.; RJ, 28 : 30-51, 1975.

\section{I - INTRODUÇÃO}

O presente trabalho surgiu da necessidade de estudar a situação atual da vacina $B C G$ por via intradérmica no Brasil. A visão do panorama geral do problema no mundo e a descrição de alguns fatos relevantes que precederam a introdução do método no país, favorecem a avaliação dos resultados do conjunto de pesquisas realizadas pela Divisão $\mathrm{Na}$ cional de Tuberculose com esta vacina e a sua repercussão nos programas de saúde pública do país.

Os cinco ensaios controlados realizados pela DNT, de 1970 a 1974, foram o fator decisivo para a aceitação da via intradérmica no Brasil, devido ao seu alto nível de eficácia.

A apresentação do número de atividades realizadas pelo programa nacional de vacinação e de suas metas referentes a 1975 e aos próximos anos, permite a apreciação quantitativa do problema.
As autcras pretendem demonstrar às enfermeiras a importância de sua contribuição nesses programas, o que torna maior a responsabilidade daquelas que atuam como coordenadoras dessas atividades. Além disso, julgam que as interessadas poderão encontrar subsídios de valor para o desenvolvimento de projetos semelhantes.

\section{II - CONHECIMENTOS ATUAIS SOBRE A VACINA BCG}

Com referência à vacina BCG, alguns pontos há sobre os quais chegou-se a uma completa concordância. Entretanto, TOMAN (23) ao examinar as questões a ela pertinentes lembra que, apesar do imenso acervo de experiências e conhecimentos acumulados durante 50 anos, através de ensaios controlados em diversas partes do mundo, a vacinação $\mathrm{BCG}$

* Auxiliar de Ensino da Escola de Enfermagem Ana Neri/UFRJ.

* Supervisoras da Seção de Enfermagem da Divisão Nacional de Tuberculose. 
CASTRO, I.B. e colaboradores - Estudo comparativo de recentes pesquisas com a vacina BCG por via intradérmica no Brasil - Análise da contribuição da Enfermeira. Rev. Bras. Enf.; RJ, 28 : 30-51, 1975.

continua sendo motivo de controvérsias. Assim é que alguns países a têm adotado como política nacional, obrigatória por lei, para toda a população vacinável, enquanto que em outros é praticamente desconhecida do público e quase um tabu entre a profissão médica.

Não obstante, a análise desses ensaios controlados sobre a eficácia do BCG (nos quais sempre foi utilizada a via intradérmica), mostra que os baixos níveis de eficácia alcançados em alguns estudos foram conseqüência da má qualidade da vacina usada. Sempre que se utilizou BCG de qualidade comprovada os resultados mostraram que a vacinação foi eficiente na prevenção da enfermidade.

$\mathrm{Na}$ vedade, a potência das vacinas BCG varia consideravelmente de um laboratório para outro, e não são raras as vacinas que contêm somente $1 \%$ de bacilos cultiváveis*. Daí a necessidade de se escolherem para a produção de vacinas, somente cepas com plena atividade metabólica, isto é, que se multiplicam com rapidez no hospedeiro. Tais vacinas induzem uma forte e duradoura sensibilidade à tuberculina nas crianças que a recebem sob a foma de pequena dose standard. Embora todas as sub-cepas de BCG existentes provenham da mesma cepa recebida de Calmette, hoje em dia não existem duas cepas de BCG no mundo que possuam características idênticas. Se uma cepa perde espontaneamente as propriedades características pelas quais foi selecionada a princípio, é muito provável que as células-mães da cepa tenham sido substituídas por células mutantes e conseqüentemente sua potência é duvidosa, tirando-lhe a capacidade de conferir proteção contra a tuberculose. A vacina liofilizada produzida pelo método do lote-semente ("seed-lot") reduz bastante o risco representado pelos $\mathrm{mu}$ - tantes, além de oferecer outras vantageins importantes, mas implica em métodos de produção e de controle de qualidade complexos, o que recomenda a li. mitação do número de centros produtores.

O estudo comparativo entre treze cepas de BCG, realizado em 1969, pela Comissão de Peritos de Padronização Biológica da OMS, em cooperação com a Unidade de Tuberculose da mesma Agência, demonstrou que a vacina brasileira (cepa Moreau - Rio de Janeiro), possui a maior virulência residual para o $\mathrm{H}$ hamster e permite maior sobrevida dos camundongos infectados com a bacilo virulento. FUNDAÇÃO ATAULPHO DE PAIVA (9) .

Lembra ainda o autor citado neste capítulo que, dentre os diversos métodos de administação da vacina BCG, a Organização Mundial de Saúde recomenda a via intradérmica, com o uso de seringa e agulha, por ser a maneira mais precisa de administrar a dose indicada em todas as pessoas. A multipuntura e a vacinação com injetor a pressão estão sendo estudados em vários países. Num projeto que conta com a assistência da OMS, vem sendo experimentada a técnica de multipuntura com o emprego da agulha bifurcada. que se utiliza muito na vacinação antivariólica.

Quanto à vacinação BCG direta, sem prova tuberculínica prévia, tem sido minuciosamente estudada e não se observou até agora efeito adverso. Outrossim, está comprovado que pode haver vantagens consideráveis na administração simultânea do BCG e cutras vacinas, sobretudo a antivariólica.

O problema da revacinação não está suficientemente estudado no homem, entertanto a proteção conferida pela primo vacinação não parece exceder de 10 anos.

O emprego do BCG contra a lepra e no tratamento da leucemia continua con-

* O esperado seria de cerca de $50 \%$ para vacinas liofilizadas. 
CASTRO, I.B. e colaboradores - Estudo comparativo de recentes pesquisas com a vacina BCG por via intradérmica no Brasil - Análise da contribuição da Enfermeira. Rev. Bras. Enf.; RJ, 28 : 30-51, 1975.

toverso e os resultados dos ensaios realizados com este fim são divergentes.

\section{III - ANTECEDENTES DO PROGRAMA DE VACINAÇÃO INTRADÉRMICA NO BRASIL}

No Brasil, de 1927 a 1969 usou-se exclusivamente a vacina BCG pela via oral, FUNDAÇÃO ATAULPHO DE PAIVA (9) de acordo com os trabalhos de Calmette. apesar da ausência de investigações controladas que provassem o seu efeito protetor. Considerando que um estudo desta natureza demandaria tempo e recursos consideráveis e cuja continuidade só poderia ser garantida por uma entidade intenacional, o Brasil solicitou essa ajuda à Organização Mundial de Saúde, em 1965. Entretanto, após estudos de viabilidade, aquela agência deliberou, no ano seguinte, pela não participação no projeto, que deveria prolongar-se por cerca de 10 anos e abranger uma população de 200 a 600 mil indivíduos. Revisão crítica das pesquisas sobre a vacinação com o BCG oral (1968). Além disso, nesta época já havia estudos controlados sobre a eficácia da vacinação intradérmica no homem, o mais conhecido dos quais é o do British Medical Research Council, em que participaram mais de 50.000 escolares, e segundo o qual o BCG conferiu $78 \%$ de proteção durante 15 anos de observação.

Não obstante, como se acredita que a via oral pode ser eficaz nos recémnascidos, a DIVISÃO NACIONAL DE TUBERCULOSE (15) a recomenda até hoje, exclușivamente para este grupo.

Como a técnica da vacinação BCG por via intradérmica é a mesma da aplicação da prova tuberculínica, a permanêncía no Brasil de uma enfermeira consultora da Organização Mundial de Saúde, de setembro de 1967 a dezembro de 1968, que em nove capitais brasileiras treinou 145 enfermeiras na referida técnica, criou a possibilidade de se implantar a vacinação intradérmica no País, AZEVEDO
(1). Com efeito, os primeiros trabalhos com esta vacina datam deste mesmo ano.

Trabalhos levados a efeito em diversos pontos do país apresentaram resultados bastante contraditórios, como mostra a TABELA I.

O primeiro ensaio, realizado por NUTFLS \& MIRANDA (17) foi patrocinado pela DNT e realizado no Parque do Xingu. O grupo escolhido foi o de índios brasileiros não reatores à prova tuberculínica e a vacina utilizada foi o BCG liofilizado fabricado pelo Instituto Pasteur. Após uma primeira tentativa, fracassada por motivos técnicos, conseguiuse uma víragem tuberculínica de $85 \%$. Não há registro de complicações.

O terceiro estudo foi patrocinado pela Secretaria de Saúde do antigo Estado da Guanabara, ROCHA (19) e foram vacinados escolares não reatores à 2 UT de PPD, com BCG liofilizado do laboratório Glaxo. Não há registro de viragem tuberculínica pós vacinal e o percentual de complicações (abcessos) foi de 6\%.

O último estudo desta tabela foi realizado simultaneamente ao primeiro ensaio da DNT. Foi patrocinado pela Secretaria de Saúde de Porto Alegre, Estado do Rio Grande do Sul, BULAMARQUI (5) sendo vacinados os reatores e não reatores à 2 UT de tuberculina com a vacina liofilizada do Laboratório Japan. A viragem tuberculínica foi de $74 \%$ entre os menores, anteriomente não reatores e reatores fracos ao PPD. Também neste estudo está omissa a informação referente a complicações.

\section{IV - ESTUDO COMPARATIVO DAS PESQUISAS PROMOVIDAS PE- LA DIVISÃO NACIONAL DE TUBERCULOSE (DNT)}

Considerando as dificuldades para a realização de um estudo controlado com a vacina oral, os resultados conclusivos de pesquisas com a via intradérmica, a difusão desta via em quase todos os paí- 
CASTRO, I.B. e colaboradores - Estudo comparativo de recentes pesquisas com a vacina BCG por via intradérmica no Brasil - Análise da contribuição da Enfermeira. Rev. Bras. Enf.; RJ, 28 : 30-51, 1975.

ses do mundo e os achados divergentes dos primeiros trabalhos acima citados, a DNT decidiu, em 1970, realizar um trabalho piloto com a vacina BCG intradérmica, que permitisse uma avaliação minuciosa da conveniência de implantar o método no país, LIMA, GERHARDT \& CASTRO (11). Nos anos seguintes foram realizados outros estudos, com vistas à expansão do método.

No segundo estudo buscava-se avaliar a conveniência da aplicação da vacina intradérmica de modo indiscriminado isto é, sem prova tuberculínica prévia.

No terceiro e no quinto estudos procurava-se validar a qualidade da vacina brasileira, sob a forma líquida e liofilizada respectivamente, bem como comparar a viragem tuberculínica induzida pela vacina oral e pela intradérmica (terceiro estudo).

No quarto estudo procurava-se avaliar a conveniência do uso dos injetores a pressão na vacinação em massa.

Em todas essas pesquisas a aplicação e a leitura das provas tuberculínicas e das vacinas foi feita por enfermeiras (auxiliados por escriturários), de modo a que os resultados obtidos pudessem ter a maior confiabilidade.

Essas enfermeiras trabalhavam com completa autonomia técnica. Os coordenadores das pesquisas acompanhavam o desenvolvimento dos trabalhos e participavam das reuniões da equipe para a avaliação do programa e discussão de problemas.

As TABELAS II e III apresentam uma visão geral da metodologia utilizada nas cinco pesquisas introdutórias realizadas pela DNT no período de 1971 a 1974 e do grau de cumprimento de suas metas.

Em todos os estudos foi utilizada a Tuberculina PPD RT 23 na dose de 2 UT. Tanto a leitura das provas tuberculínicas como as observações das lesões vacinais foram feitas pelo método de "leitura cega", isto é, a enfermeira desconhecia quais as crianças do grupo de estudo e quais as do grupo controle. A observação das lesões vacinais foi feita por dez semanas consecutivas.

Foram escolhidos para figurar na Tabela III, os dados referentes à quinta e à décima semanas, por corresponderem à fase mediana e à terminal do trabalho.

Foi estabelecida uma cobertura mínima de $90 \%$ para a aplicação e leitura das provas tuberculínicas pré e pósvacinal e para as observações semanais das lesões vacinais. Para a vacinação a meta era de $95 \%$.

C alto grau de cumprimento das metas deve-se ao compromisso da equipe em relação ao tabalho; no segundo e quarto estudos apresentaram-se dificuldades especiais ligadas à organização e ao funcionamento das escolas, que eram coletividades abertas. Na quarta pesquisa foi necessário estabelecer-se um rendimento das atividades muito abaixo da capacidade dos operadores, de modo a que as metas pudessem ser cumpridas.

Os números absolutos da Tabela III diferem ligeiramente do dado correspondente nas demais tabelas, pois correspondem à informação bruta, enquanto que nas outras tabelas já havia sido feito o descarte das fichas, com registro de falhas técnicas.

O primeiro estudo LIMA, GERHARDT \& CASTRO (11) foi feito no $1 .^{\circ}$ semestre de 1970, sendo aplicada a prova tuberculínica em 4046 crianças $(72,6 \%$ da população a ser trabalhada). Destes tiveram suas provas lidas $3934(97,2 \%)$. Dos 2700 escolares que constituiam a população a vacinar, $2538(93,7 \%)$ foram incluídos no início do estudo, quando 1985 crianças não reatoras foram vacinadas com o BCG liofilizado do Laboratório Japan e em 424, também não reatoras, foi inoculado soro fisiológico, sendo este o grupo controle. Na quinta semana foram observadas 1845 crianças $(75,4 \%)$ e na décima $1799(71,0 \%)$. O reteste foi aplicado em 2254 escolares 
CASTRO, I.B. e colaboradores - Estudo comparativo de recentes pesquisas com a vacina BCG por via intradérmica no Brasil - Análise da contribuição da Enfermeira. Rev. Bras. Enf.; RJ, 28 : 30-51, 1975.

$(90,0 \%$ dos vacinados $)$ e destes 2137 $(9.1,8 \%)$ tiveram seus testes lidos.

O segundo estudo, sobre a vacinação BCG em alérgicos e analérgicos, foi realizado no segundo semestre deste mesmo ano LIMA, GERHARDT, CASTRO \& MESQUITA (12). A população selecionada era de 2158 escolares e o número de testes aplicados foi de 2079 (96.3\%). Neste grupo, 2002 crianças $(96,2 \%)$ tiveram seus testes lidos, sendo 1951 $(97,5 \%)$ vacinados com o BCG liofilizado do Labcratório Japan. Desses, 1179 eram não reatores e formaram o grupo controle e 772 eram reatores e constituíram o grupo de estudo. Dentre os vacinados, foram observados 1836 escolares na quinta semaria e $1337(94,1 \%)$ na décima. No reteste foi aplicada a prova tuberculínica em 1942 menores $(99,5 \%)$ dos quais $1769(90,6 \%)$ tiveram seus testes lidos.

O terceiro estudo LIMA, GERHARDT, CASTRO \& MESQUITA (13) foi realizado no segundo semestre de 1972, quando o Laboatório da FUNDAÇÃO ATAULPHO DE PAIVA (FAP) já produzia a vacina intradérmica líquida e destinava-se à comparação da alergia tuberculínica induzida por três tipos de vacina, a saber: a Glaxo (intradérmica e liofilizada, que já havia sido utilizada nos Ensaios de Vacinação Intradérmica nas Capitais Brasileiras), a FAP (intradérmica e líquida) e a oral, do mesmo laboratório brasileiro. Os três grupos foram divididos por sorteio aleatório. Feito o teste pré-vacinal, foram vacinados $80 \%$ dos não reatores de cada grupo, sendo os $20 \%$ restantes reservados para o respectivo grupo controle. A população a vacinar era fomada por 2301 menores, dos quais foram vacinados $2272(98,7 \%)$. Após o descarte das fichas, antes do tratamento estatístico, os grupos ficaram assim constituídos: grupo da vacina Glaxo era formado por 813 crianças, enquanto que 206 crianças formavam o grupo controle. O segundo grupo, 783 escolares vacinados com a vacina líquida da
FAP, para uso intradérmico, possuia 198 escolares no grupo controle. No terceiro grupo vacinaram-se 182 escolares, com a vacina da FAP, líquida para uso oral e o grupo controle contou com 49 menores. O produto utilizado para o grupo controle foi o soro fisiológico. Foram convocados para este estudo 4341 escolares e deste total, $3935(90,8 \%)$ foram submetidos à prova tuberculínica, sendo que compareceram para leitura 3832 $(97,4 \%)$. Na quinta e na décima semanas observaram-se $2231(98,2 \%)$ e 2214 $(97,4 \%)$ do total de alunos vacinados. No reteste, foram aplicados 2258 testes $(99,4 \%$ dos vacinados) e destes foram lidos $2198(97,3 \%)$.

No quarto estudo, GERHARDT (10) efetuado em 1974, com os injetores a pressão, foi empregada a vacina BCG para uso intradérmico, fabricado pela FAP, já então sob a forma liofilizada. O controle realizado no Seruminstitut de Copenhagen com o "seed-lot" brasileiro já havia provado que esta vacina continha, na dose empregada para a vacinação, um número suficiente de germes.

Nesta pesquisa utilizaram-se três tipos de instrumentos para a vacinação: a seringa Omega, o Ped-O-Jet e o PanJet, sendo que com o Ped-O-Jet foram aplicadas duas concentrações vacinais diferentes. Os quatro grupos foram selecionados por sorteio aleatório. Faziam parte do grupo de trabalho 3711 escolares. Destes, foram submetidos à prova tuberculínica 3419 crianças $(91,9 \%)$. Dos testes aplicados, foram lidos 3404 $(99,5 \%)$. Dessa população, foram vacinados 3384 crianças $(99,4 \%)$, assim distribuídas: 844 escolares foram inoculados com a seringa. A dose utilizada foi 0,1 $\mathrm{mcg} \in \mathrm{m} 0.1 \mathrm{ml}$. Este foi considerado o grupo controle, do qual faziam parte 580 escolares não reatores e 264 reatores. Com o Injetor 1 (Ped-O-Jet) foi utilizada a mesma dose do grupo controle, em 871 escolares, sendo que 594 eram não reatores à prova tuberculínica e 277 eram rea- 
CASTRO, I.B. e colaboradores - Estudo comparativo de recentes pesquisas com a vacina BCG por via intradérmica no Brasil - Análise da contribuiçäo da Enfermeira. Kev. Bras. Enf.; F.J, $28: 30-51,1075$.

tores. C'om o Injetor 2 (Ped-O-Jet) foi utiiizada a dose de $0,14 \mathrm{mcg}$ em $0,1 \mathrm{ml}$. O total de vacinados foi de 860 menores, sendo 591 não reatores e 269 reatores. Com o Injetor 3 (Pan-Jet) usou-se a mesma dose do Injetor 2 em 803 crianças, das quais 553 eram não reatores e 256 eram reatores. Na quinta e na décima semanas, observaram-se 3256 $(36,2 \%)$ e $3278(96,8 \%)$ crianças respectivamente. Na prova pós-vacinal foram retestadas 3257 crianças $(96,2 \%)$ e destas, compareceram para leitura 3104 $(95.3 \%)$.

No quinto estudo, SANTOS NEVES (22) para comparação da alergia pós-vacinal induzida pelas vacinas intradérmicas, líquida e liofilizada, da FAP, foram vacinados apenas escolares reatores à prova tuberculínica. O total de crianças previsto nara o trabalho era de 754 e destas $724(96,0 \%)$ foram submetidas à prova tuberculínica e lidas $718(99,1 \%)$. O número de menores selecionados para a vacinação foi de 366 , sendo inoculados $360(98,3 \%)$, sendo 172 com o BCG líquido, e que constituíram o grupo controle, e 188 com o BCG liofilizado e que constituíram o grupo de estudo. $\mathrm{Na}$ quinta e na décima semanas foram o'sservadas 330 e 331 crianças $(91,7 \%$ e $91 \% \%$ respectivamente). No reteste foram aplicadas 350 provas tuberculínicas (97,2\% dos vacinados) e todas lidas.

Nas TABELAS IV e $\mathrm{V}$ apreciam-se os resultados das cinco pesquisas analisadas. conforme a evolução da lesão vacinal e o reteste.

Na primeira pesquisa (Ação Programada), do total de vacinados, $1845 \mathrm{me}-$ nores foram observados na quinta semana e destes $373(20,2 \%)$ eram portadores de úlcera. Na décima semana, dentre os 1799 observados, $667 \quad(37,1 \%)$ a.presentavam cicatriz vacinal. Foram encontrados apenas dois casos de enfartamento ganglionar. $O$ resultado da prova tuberculínica pós-vacinal, realizada após dez semanas de vacinação, foi o seguinte: dos 1713 escolares vacinados, e que tiveram suas provas lidas, $447(26,1 \%)$ continuaram não reatores e reatores fracos, enquanto que 1266 $(73,9 \%)$ passaram a reatores fortes. Do grupo controle, 413 $(97,4 \%)$ escolares continuaram não reatores ou reatores fraccs e $11(2,6 \%)$ passaram a reatores fortes.

$\mathrm{Na}$ segunda pesquisa ("vacinação em alérgicos e analérgicos") dentre os 1951 menores vacinados, 1835 foram observados na quinta semana sendo constatada a presença de úlcera em 163 (8,9\%) crianças. Em 1837 observados na décima semana, foram encontradas $868(47,3 \%)$ cicatrizes vacinais. Registraram-se apenas três casos de reações indesejáveis, todos ocorridos em reatores à prova prévia. Os resultados das provas tuberculínicas pós-vacinais mostraram que para 6£3 menores reatores fracos e fortes que constituiram o grupo de estudo 17 (24\%) permaneceram reatores fracos, $676(97,6 \%)$ foi o total de reatores fortes. O grupo controle constituído de 1075 não reatores à prova tuberculínica prévia, 202 (18,7\%) não apresentaram viragem e 874 passaram a reatores fortes dando um percentual de viragem de $81,3 \%$.

No terceiro estudo (comparação da a.ergia induzida por três tipos de vacina), na quinta semana de observação cla lısão vacinal, dentre os 792 escolares examinados, vacinados com o BCG do Laboratório Glaxo $253 \quad(32,3 \%)$ eram portadores de úlceras e neste mesmo grupo, na décima semana foram observados $7 £ 3$ crianças, das quais $438(55,2 \%)$ iá pcissuiam cicatriz.

Do total de vacinados com a vacina líquida intradérmica da Fundação Ataulpho de Paiva na quinta semana foram observados 764 esco!ares e dentre eles 206 (27\%) apresentavam úlceras; na décima semana verificou-se, no mesmo número de observados, a presença de $455(59,6 \%)$ cicatrizes. Quanto aos re- 
CASTRO, I.B. e colaboradores - Estudo comparativo de recentes pesquisas com a vacina BCG por via intradérmica no Brasil - Análise da contribuição da Enfermeira. Rev. Bras. Enf.; RJ, 28 : 30-51, 1975.

sultacios clas provas tuberculínicas pósvacinais com o BCG do Laboratório Glaxo, $150(20,0 \%)$ escolares mantiveram-se não reatores ou reatores fracos, ençuanto que em $631(80 \%)$ observouse a viragem tuberculínica (entre os 789 escolares que tiveram seus retestes lidos). No grupo controle $186(95,4 \%)$ esco'ares continuaram reatores fracos e não reatores e $3(4,6 \%)$ passaram a reatores fortes, do total de 135 que tiveram o reteste lido.

Do grupo vacinado com o BCG FAP (vacina líquida intradérmica) $6(8,2 \%)$ escolares não apresentaram viragem tuberculínica, enquanto que em $701(91,8 \%)$ observou-se a viragem. Foram observaGos apenas dois casos de reações indesejáveis. Do grupo controle 176 (91,7\%) escolares continuaram não reatores e reatores fracos, enquanto $16(8.3 \%)$ reagiram à prova tuberculínica, do total de $102(100 \%)$ com retestes lidos. No grupo vacinado com BCG FAP oral observou-se que $114(55,5 \%)$ continuaram não reatores e reatores fracos.

Na quarta pesquisa (sobre os Injetores a pressõo), achou-se que na quinta semana de observação do grupo vacinado com seringa (grupo controle) $83(10,3 \%)$ criancas apresentavam úlcera do total c.e 812 cbservados. E na décima semana de igual número de observados, 500 $(61,5 \%)$ apresentaram cicatriz; nos vacinados com o Injetor 1 (Ped-O-Jet) cbservou-se 825 escolares na quinta semana e neste grupo examinado 66 $(\&, 0 \%)$ possuíam úlcera e na décima semana dentre os 830 observados 708 $(85,3 \%)$ tinham cicatriz; nos vacinados com o Injetor 2 (Ped-O-Jet) foram observados na quinta semana 834, dos quais $3 \hat{3}$ apresentavam úlcera $(4,3 \%)$ e dos 833 examinados na décima semana $7 \pm 6(83,5 \%)$ tinham cicatriz; nos vacinados com o Injetor 3 (Pan-Jet) foram observados 766 escolares com a presença de $85(11,0 \%)$ úlceras e na décima semana, dos 783 observados $467 \quad(59,6 \%)$ contavam cicatrizes. Neste estudo foram observados cinco casos de reações indesejáveis ocorridas no grupo controie (vacinados com a seringa). Dos 803 ( $100 \%)$ escolares que fizeram parte deste grupo, $110(13,6 \%)$ continuaram não reatores e reatores fracos enquanto $6 \approx 3$ $(26,4 \%)$ foram reatores ao teste pósvacinal.

No grupo do Injetor $1,242 \quad(29,4 \%)$ escolares vacinados pcr este instrumento não apresentaram viragem tuberculínica, enquanto $573(69,6 \%)$ apresentaram, dos $325(100 \%)$ vacinados.

No grupo do Injetor 2 - vacinaramse 820 escolares com este injetor dos quais $257(31,3 \%)$ mantiveram-se não reatores e reatores fracos enquanto 583 $(68.7 \%)$ tiveram viragem tuberculínica.

No grupo do Injetor $3-185$ ( $23,8 \%)$ menores foram não reatores e reatores fracos no teste pós-vacinal enquanto 592 $(76,2 \%)$ foram reatores fortes.

No quinto estuảo (comparação entre as vacinas líquidas e a liofilizada de uso intradérmico da FAP) na quinta semana de observação dentre os vacinados com vacina llquida $47(28,3 \%)$ possuíam úlcera, de um total de 166 observados e na ciécima semana encontrou-se 102 (61 $\mathrm{S} \%$ ) crianças com cicatrizes (dos 165 observados). Nos 188 vacinados com a vacina liofilizada e observados na quinta semana, $38(20,8 \%)$ possuiam úlcera e na décima semana de igual númro de observados 149 (84,0\%) apresentaram cicatrizes. Neste estudo observaram-se três casos de reações indesejáveis. sendo dois deles atribuídos à vacira líquida e um à vacina liofilizada. Quanto à viragem tuberculínica, dos 166 inocu'ados com a vacina líquida intradormica e que constituíram o grupo controle $9(5,4 \%)$ não apresentaram viragem e em 157 menores o percentual de viragem foi $94,6 \%$. Dos 176 vacinados com a vacina liofilizada 26 $(14,1 \%)$ continuaram não reatores e 
CASTRO, I.B. e colaboradores - Estudo comparativo de recentes pesquisas com a vacina BCG por via intradérmica no Brasil - Análıse da contribuição da Enfermeira. Rev. Bras. Enf.; RJ, 23 : 30-51, 1975.

reatores fracos e $158(85,9 \%)$ passaram a reator forte.

Comparando-se os dados dos cinco estudos, verificamos que o percentual de úlceras variou de 4.3 a $32,3 \%$, sendo que os percentuais iguais ou inferiores a $11 \%$ correspondem aos programas de vacinações indiscriminadas, o que se explica pelo fato de que a evo'ução da lesão vacinal em indivíduos já infectacios (naturalmente) se faz de modo aceleraco, de modo que, em muitos deles, na quinta semana já se encontra cicatrizado.

$\mathrm{Na}$ comparação dos resultados de sensibilidade tuberculínica pós-vacinal, verificamos que o percentual de viragem nos vacinados com injetores a pressão, foi menor do que nos demais estudos em que se utilizou a seringa como instrumento para vacinação.

No grupo controle não vacinado o percentual de viragem tuberculínica foi menor que $10 \%$ ( $1 .^{\circ}$ e $3 .^{\circ}$ estudos $)$.

No quinto estudo constatamos uma pequena diferença na viragem entre a vacina líquida e a liofilizada que é naturalmente superada pelas vantagens da utilização da última na prática de saúde pública. Com a vacina FAP liofilizada que é atualmente utilizada em todo o território nacional, observa-se no grupo vacinado que $84,0 \%$ das lesões encontraram-se cicatrizadas na quinta sema$n a$ e a proporção de reações indesejáveis fci de $0.5 \%$ ou seja, 5 por mil.

V -- CONTRIBUIÇÃO DA ENFERMEIRA

Procuraremos avaliar a contribuição da enfermeira conforme o grau de sua participação no conjunto das cinco pescuisas realizadas pela DNT e a qualidade desta participação.

Das onze enfermeiras que participarom das cinco pesquisas, cinco participaram da primeira (Ação programada de vacinação $\mathrm{BCG}$ ), três da segunda (Vacinação em alérgicos e analérgicos), nove da terceira (Comparação da aler- gia induzida por três tipos de vacina), sete da quarta (Estudo com os injetores a pressão) e três da quinta (Comparação das vacinas líquida e liofilizada). Por outro lado, vemos, na TABELA VI, que de um total de onze enfermeiras, duas participaram das cinco pesquisas. Outra participou em quatro pesquisas (8:10) três enfermeiras participaram de três pesquisas $(6: 10)$. Duas enfermeiras participaram de duas pesquisas (4:10) e três enfermeiras de apenas uma pesquisa $(2: 10)$. Dos dados apresentados podemos concluir que $50 \%$ das enfermeiras participaram de mais da metade dos estudos e que o conjunto das pesquisas foi desenvolvido por um pequeno grupo (11 enfermeiras) o que é muito convenientc, porque quanto menor o número de pessoas envolvidas na sua execução menor será a margem de erro.

A qualidade da participação da enfermeira é atestada pela reprodução dos resultados de pesquisas internacionais, pelo alto grau do cumprimento das metas estabelecidas para os trabalhos de campo (Tabela III), por sua atuação como assessora na elaboração dos cinco protocolos de pesquisa, pela redação de relatórios minuciosos e precisos dos trabalhos de campo, que foram utilizados constantemente na elaboração dos relatórios das pesquisas e por sua participação em co-autoria na publicação dos resultados de três das cinco pesquisas.

Os resultados obtidos nas pesquisas aqui relatadas não trouxeram contribuição científica nova, que pudesse aumentar os conhecimentos já existentes sobre o assunto, pois os mesmos achados já haviarn sido encontrados em programas realizados fora do Brasil. Entretanto a reprodução, em território nacional, dos resultados de trabalhos científicos de alto nível, demonstrou nossa auto-suficiência técnica no assunto. Vale lembrar que todos esses estudos foram realizados sem assessoria de enfermagem de fora do país. 
CASTRO, I.B. e colahoradores - Estudo comparativo de recentes pesquisas com a vacina BCG por via intradérmica no Brasil -- Análise da contribuição da Enfermeira. Rev. Bras. Enf.; RJ, 28 : 30-51, 1975.

O aprimoramento dos conhecimentos das enfermeiras da DNT, no decorrer clos trabaihos, aliado a uma ampla visão dos aspectos práticos do assunto, habilitaram-nas a desenvolver programas de treinamento e supervisão de pessoal em todas as regiões do país. Essa vantagem decorreu da participação da enfermeira desde a elaboração do projeto de pesquisa até a execução do trabalho de campo e à avaliação dos resultados.

Por outro lado, o baixo percentual de compiicações, garantido pela atuação eficiente, possibilitou a expansão do programa a outras capitais brasileiras. Entre os métodos de vacinação utilizados, constatou-se que a via oral não é como se pensava, a mais prática, pois a administração correta da vacina, que deve ser feita nos indivíduos com o estômago vazio, de preferência em jejum, permitindose a alimentação apenas uma hora depois, acarretou enormes problemas operacionais, resultando em um rendimento muito inferior ao da vacinação por via intradérmica. Por outro lado, se estes cuidados forem deixados por conta das crianças ou de seus acompanhantes não se saberá a proporção de vacinações corretas. A vacinação BCG com injetores a pressão é considerada freqüentemente como o processo mais prático para a vacinação em massa. No Brasil o aparelho é usado principalmente para a vacinação antivariólica e contra a meningite. Dentre as vantagens operacionais que o método oferece podemos citar: a rapidez da inoculação e a aplicação indolor, o que acarreta boa aceitação pelo público; além disso, o treinamento para seu manejo é bastante simples. Entretanto, no quarto estudo realizado pela $D N T$, utilizando-se tal instrumento, apre- sentaram-se algumas dificuldades técnicas como insuficiência da dose inoculada, por condições do próprio injetor ou cefeito da aplicação e penetração subcutânea em pessoas de pele pouco espessa; a dificuldade de manutenção dos aparelhos, interfere no rendimento do método e torna difícil sua utilização em locais que não existam técnicos com expcriência na sua manutenção. Um método que poderá vir a ser utilizado nos programas de vacinação em massa é a multipuntura, cuja execução é a mais simples dentre as técnicas de administração por via parenteral, se os estudos que estão sendo realizados comprovarem sua eficiência.

Também em relação aos aspectos referentes à técnica, há uma busca no sentido da simplificação, visando-se a facilitar a vacinação em massa. O uso da panela de pressão, em substituição à autoclave, resolveu o problema da esterilização do material nos pequenos centros. O acondicionamento de seringas e agulhas $\mathrm{em}$ pacotes, elimina o problema de aquisição de material como: caixas metálicas ou cubas com tampas, a confecção de alcochoados, etc. Problema ainda de difícil solução é a da Seringa Omega, importada, pois até o momento as seringas nacionais fabricadas para esta finalidade ainda não conseguiram preencher os requisitos mínimos indispensáveis à aplicação de uma dose padronizada da vacina.

\section{VI - AN Á LISE DAS ATRIBUIÇÕES DA ENFERMEIRA, SEGUNDO OS COMPORTAMENTOS E ATITU- DES EXIGIDOS *}

O nível de complexidade da participação da enfermeira nessas pesquisas

* Os objetivas educacionais podem ser determinados como pré-requisitos, ou como meta do aprendizado, isto é, servem como padrões para os diversos tipos de avaliação - diagnóstica, formativa e somativa. Os objetivos de pré-requisitos correspondem às capacidades 
CASTRO, I.B. e colaboradores - Estudo comparativo de recentes pesquisas com a vacina BCG por via intradérmica no Brasil - Análise da contribuição da Enfermeira.

Rev. Bras. Enf.; RJ, 28 : 30-51, 1975.

pode ser demonstrado pela aplicação da taxionomia de objetivos educacionais de Bioom, às atribuições das quais se desincumbiu.

Em sua taxionomia, Bloom (2) considera três domínios: o cognitivo, o psicomotor e o afetivo.

A área cognitiva abrange seis níveis de complexidade em um grau crescente de generalidade e abstração, a saber: conhecimento, compreensão, aplicação, análise, síntese e avaliação e se refere à seleção, na memória, das informações mais apropriadas à resolução de um problema.

As capacidades exigidas para o desempenho das atribuições estabelecidas para as enfermeiras nas cinco pesquisas estudadas são listadas a seguir:

- comunicar-se usando a terminologia relacionada à prova tuberculínica e à vacinação com o BCG por via intradérmica. Foram identificados pe10 menos 30 termos.

-- utilizar dados específicos como doses de PPD e BCG, prazo de leitura da prova tuberculínica, prazo para o reteste, prazo de validade dos produtos, margens de erro admitidas na comparação entre as leituras das diversas enfermeiras, cumprimento mínimo das metas operacionais, características da população a ser trabalhada.

- proceder de maneira adequada à conservação dos produtos biológicos.

- reconhecer o código de cores e siglas convencionais para cada tipo de atividade.

- descrever a evolução da reação alér- gica à tuberculina e a evolução da lesão vacinal.

- c'assificar as medidas das leituras das reações tuberculínicas.

- citar os critérios quantitativos e qualitativos de avaliação dos trabalhos.

- enumerar as contra-indicações da vacina $B C G$ intradérmica.

- descrever princípios elementares dos mecanismos imunológicos.

- traduzir a taxa de infecção tuberculosa.

- interpretar os histogramas das provas tuberculínicas de cada operador.

- interpretar os diagramas de dispersão das leituras de duas operadoras.

- prever o pessoal e o material necessários à execução das pesquisas.

- aplicar a metodologia do projeto da pesquisa às atividades de campo.

- formular as atribuições de todo o pessoal envolvido na execução da pesquisa.

- analisar os dados estatísticos referentes ao trabalho executado.

- participar da elaboração dos projetos das pesquisas e das comunicações dos seus resultados.

- elaborar relatos de comunicação sobre a participação da enfermeira nesses estudos.

- progranar atividades de campo.

- elaborar cronogramas de metas.

- identificar da necessidade de aplicar as ordens médicas permanentes à criança portadora de lesão vacinal de evolução anormal.

- avaliar a qualidade do trabalho executado.

- avaliar o grau de cumprimento das metas.

exigidas ao se inciar o programa. A a avaliação formativa é paralela ao desenvolvimento das atividades e a somativa corresponde à verificação da consecução dos objetivos visados. A.ssim as atribuições do pessoal podem ser analisadas com base na mesma taxionomia, pois, na medida em que descrevem as atividades próprias de cada elemento da equipe, correspondem a objetivos de pré-requisitcs. 
CASTRO, I.B. e colaboradores - Estudo comparativo de recentes pesquisas com a vacina BCG por via intradérmica no Brasil - Análise da contribuição da Enfermeira. Rev. Bras. Enf.; RJ, 28 : 30-51, 1975.

- avaliar os resultados da pesquisa em termos de evolução da lesão vacinal e viragem tuberculínica.

- identificar as vantagens e desvantagens operacionais das diferentes vias, métodos e técnicas utilizadas nas diversas pesquisas.

A área psicomotora envolve comportamentos dependentes do sistema neuromuscular. Foram as seguintes as atividades das enfermeiras relacionadas a essa área:

- preparar o material necessário às atividades do trabalho de campo.

- observar a pápula resultante da aplicação da prova tuberculínica ou do BCG intradérmico.

- observar as lesões vacinais, de acordo com as diversas fases de evolução que se apresentam e qualificar esses achados.

- fazer a triagem das crianças a serem examinadas, de acordo com o protocolo da pesquisa.

- fazer aplicações e leituras seriadas de provas tuberculínicas e vacinas BCG com adaptação aos incidentes ocorridos.

- atender a possíveis reações gerais e imediatas apresentados pelas crianças.

- prccessar dados estatísticos.

- supervisionar atividades simultâneas e tomar providências paralelas cabíveis.

- coordenar as atividades de campo e de apoio.

A área afetiva diz respeito à extensão e à profundidade em que uma pessoa adota como próprios os valores de outra pessoa ou da sociedade, os quais o levam a formar julgamentos ou a determinar sua conduta.

As atitudes e comportamentos exig1dos das enfermeiras que participaram dos citados estudos, foram: aceitar a responsabilidade de levar a bom termo a execução da pesquisa. preocupar-se com o bem-estar das crianças incluídas na pesquisa e de suas famílias.

- estabelecer boas relações com os companheiros de trabalho.

- adotar sistematicamente precauções adequadas.

- manter uma atitude inquisitiva.

- manifestar alto grau de compromisso em relação à finalidade das pesquisas.

demonstrar desejo de levar os recursos da ciência biomédica às populações.

\section{VII - SITUAÇÃO ATUAL DO PRO- GRAMA DE VACINAÇÃO BCG INTRADÉRMICA NO BRASIL}

Face aos resultados favoráveis do primeiro estudo realizado pela DNT - em 1970, foi iniciado no segundo semestre do mesmo ano, utilizando-se os mesmos critérios do primeiro estudo, o "Ensaio de Vacinação BCG Intradérmico nas Capitais Brasileiras". Neste ano foram incluídas sete cidades e no ano seguinte mais sete incoporaram-se ao ensaio; no final de 1973 a vacina BCG já havia sido implantada em todos os Estados e Territórios da Federação. Após o estudo de 1971, quando se vacinaram reatores e não reatores à prova tuberculínica, tendo sido demonstrado não haver objeções de ordem técnica à vacinação indiscriminada e havendo entretanto grandes vantagens operacionais, passou-se ao uso da vacina sem teste prévio entre os escolares, utilizando $0,1 \mathrm{ml}$ do produto vacinal.

Em 1974, a fim de que o BCG intradérmico pudesse ser incluído nos programas gerais de vacinação, passou-se a utilizá-lo também na população de 31 dias a três meses, utilizando-se $0,05 \mathrm{ml}$ 
CASTRO, I.B. e colaboradores - Estudo comparativo de recentes pesquisas com a vacina BCG por via intradérmica no Brasil -- Análise da contribuição da Enfermeira. Rev. Bras. Enf.; RJ, 28 : 30-51, 1975.

(meia dose da vacina) e no grupo de 4 meses a 7 anos utilizando-se a dose completa.

A Tabela VII informa o número e o percentual de vacinados por região até 1974, a vacinar em 1975 , e a vacinação a ser realizada nos anos seguintes, permitindo cobrir $80 \%$ da população brasileira de 0 a 14 anos. *

Vemos que na região Norte, até 1974 de uma população-alvo 1.429 .773 foram vacinados $24 \%$ dessa população e em 1975 está prevista a vacinação de $26 \%$, restando cobrir nos anos posteriores 707.585 , o que corresponde a $50 \%$ da meta prevista.

$\mathrm{Na}$ região Nordeste $80 \%$ da população menor de 15 anos é de 10.158.419; $14 \%$ deste grupo foi vacinado até 1974. Em 1975 prevê-se vacinar $18 \%$ da população citada. Para atingir a cobertura de $80 \%$ restam a vacinar 6.801 .663 , o que corresponde a $68 \%$.

No Sudeste 12.320 .724 representam $80 \%$ da população menor de 15 anos. Vacinou-se deste grupo $16 \%$, até o ano de 1974. Para o ano de 1975, o número de vacinados deverá atingir mais $20 \%$ daquela população. Restam a vacinar nos anos seguintes $7.846 .597(64 \%)$ da população da região.

Na região Sul $80 \%$ da população de menores de 15 anos correspondem a 7.5§7.167. Já foram vacinados $17 \%$ deste total, até o ano de 1974. Em 1975 deverão ser vacinados mais $21 \%$ desta popu'ação. Restam a vacinar 4.712.457 $(62 \%)$ para atingir-se o total de crianças naquela faixa etária.**

$\mathrm{Na}$ região Centro-Oeste $80 \%$ da população de menores de 15 anos a ser vacinada é de 1.829 .662 habitantes, dos quais $17 \%$ foram vacinados até 1974 .
Em 1975 deverão ser vacinados $18 \%$ e a previsão para os anos seguintes é de 1.185.410 crianças, o que corresponde a $65 \%$ da população prevista.

Nesta tabela observamos que até 1974 o maior grau de cobertura de vacinação ocorreu na região Norte, estando previsto para o ano de 1975, também nesta região a maior cobertura.

O menor percentual de vacinados ocorreu na região Nordeste, onde se vacinou até $197414 \%$ da população-alvo. Em 1975 também está prevista nesta área a menor cobertura. Para os anos seguintes a região Nordeste deverá vacinar $68 \%$ da população-alvo, o que representa o maior percentual das cinco regiões citadas. Em números absolutos o maior volume de trabalho realizado e previsto corresponde à região sudeste, onde se localiza a maior parte da população de 0 a 14 anos.

A Tabela VIII mostra o número de pessoas treinadas diretamente pelas enfermeiras da DNT em BCG intradérmico, de acordo com as regiões geográficas do país, no período de 1971 a 1974 e o tipo de treinamento recebido.

Considerando as enfermeiras como agentes multiplicadores (encarregadas de expandir o programa estabelecido), justifica-se o interesse da DNT na preparação adequada daquele profissional.

Assim sendo, o treinamento ministrado a 83 enfermeiras aqui referidas foram realizados em Seminários de $P P D$ e ECG (na Sede da DNT e em outros locais). Mais sessenta foram habilitadas em treinamentos individuais, o que perfaz um total de 143 enfermeiras, ou seja, uma para 120.000 pessoas vacinadas (17.335.094:143).

Verificamos também que na região

* A meta de vacinação com o BCG intradérmico é cumulativo porque a proteção conferida dura cerca de 10 anos.

* O programa de vacinação do Estado do Rio Grande do Sul recebeu ajuda técnica direta da Organização Pan-Americana de Saúde. 
CASTRO, I.B. e colaboradores - Estudo comparativo de recentes pesquisas com a vacina BCG por via intradérmica no Brasil - Análise da contribuição da Enfermeira. Rev. Bras. Enf.; RJ, 28 : 30-51, 1975.

Sudeste, onde foi treinado o maior número de enfermeiras, o número de vacinados foi superior ao das demais regiões.

\section{VIII - CONCLUSÕES}

1 - A realização de pesquisas é o único meio de se alcançar auto-suficiência técnica, pois, mesmo a repetição de estudos feitos no exterior, promove a organização de recursos e o aperfeiçoamento de métodos e técnicas, no que se baseia o prestígio das instituições e a confiabilidade dos resultados dos estudos por elas promovidas.

2 - A implantação de novos métodos ou técnicas de saúde pública deve ser cercada de cuidados especiais que protejam o programa de eventuais fracassos. Parte importante dessas precauções é a execução dos trabalhos iniciais por profissionais de alto nível.

3 - Há vantagem na utilização de enfermeiras nessas pesquisas, porque sua presença além de garantir a consecução dos objetivos visados, permite a formação de grupos capazes de treinar o pesscal necessário à expansão do programa a todo o país, bem como assessorar as autoridades sanitárias na programação das atividades. Uma vantagem paralela é o aperfeiçoamento das habilidades deste grupo quanto à metodologia da pesquisa .

\section{IX - RECOMENDAÇÕES}

- Que os Serviços de Saúde ao promoverem suas pesquisas, pensem na participação da enfermeira, desde a elaboração dos projetos até a produção do documento de comunicação dos resultados.

- Que as enfermeiras procurem participar das pesquisas promovidas pelos serviços onde trabalham, como meio de se iniciarem na teoria e na prática da metodologia científica ou de nela se aperfeiçoarem, de modo a poderem lançar-se na pesquisa de enfermagem com maior segurança.

\section{BIBLIOGRAFIA}

1. AZEVEDO, Antonia Séve e col. A prova tuberculínica e sua utilização no Brasil - Apresentado no XX Congresso Brasileiro de Enfermagem, Recife, 1968, (mimeografado).

2. BLOOM, Eenjamin S; KRATHWOHL, David R. \& MASIA, Bertram B. Taxionomia de Objetivos Educacionais Vol. 1 e 2. Edit. Globo Porto Alegre, 1974.

3. BRASIL - DIVISĀO NACIONAL DE TUBERCULOSE -- Prova Tuberculínica em Saúde Pública $-2 .^{a}$ recomendação. Kev. Div. Nac. Tuberc. Rio de Janeiro 12 (47): 219230, 3. ${ }^{\circ}$ trim, 1968.

4. BRASIL - DIVISÃO NACIONAL DE TUEERCULOSE - Ação antitu- berculose a nivel periférico (M-4). Rio de Janeiro, 1974.

5. BULAMARQUE, Clélia; e col. Programa de investigação sobre a praticabilidade da vacinação BCG intradérmica direta em criancas de escolas primárias. Rev. Bras. Enf., Rio de Janeiro, 24 (6) : 125-48, out/dez., 1971.

6. COELHO, Maria Alice Machado; e col. 'Taxionomia de Objetivos col. Taxioncmia de Objetivos Educacionais. Seminário de Diđática Aplicada ao Ensino Superior. 14-18 de abril de 1975 (material mimeografado).

7. DECK, F. \& GULD. J. La prueba tuberculínica estandar de la OMS. 
CASTRO, I.B. e colaboradores - Estudo comparativo de recentes pesquisas com a vacina BCG por via intradérmica no Brasil - Análise da contribuição da Enfermeira. Rev. Bras. Enf.; RJ, 28 : 30-51, 1975.

In: OMS/TR Guia técnica. 3/63 OPSiOMS -CD/TB/8/69. Washington, 1969.

8. FERREIRA, Emerson - Vacinação BCG intradérmica -. ensaio de aplicação do método. Rev. Serv. Nac. Tuberc, Rio de Janeiro, 13. (52) : 377-384, out/dez, 1969.

9. FUNDAÇAO ATAULPHO DE PAIVA. Vacina BCG Brasileira preparada com a Cepa. Rio de Janeiro. Rio de Janeiro, 1972 (Informe Técnico).

10. GERHARDT FILHO, Germano. Aplicação da Vacina BCG produzida com estirpe Moreau. de forma indiscriminada, por via intradérmica, com seringa e injetores a pressão. Dissertação de Mestrado para apresentação à Faculdade de Medicina da Universidade Federal do Rio de Janeiro, 1975.

11. LIMA, Laurênio Lins de, GERHARDT FILHO, Germano \& CASTRO, Ieda Barreira e. Ação programada de vacinação $B C G$ intradérmica. Rev. Div. Nac. Tuberc. Rio de Janeiro (61), 1972.

12. Ensaio da vacinação BCG intradérmica em escolares das capitais biasileiras. Protocolo. Rev. Div. Nac. Tuberc. Rio de Janeiro (68): 437-447, 1973.

13.

MESQUITA, João Ferreira. A vacinação E,CG intradérmica em alérgicos e analérgicos. Rev. Div. Nac. Tuberc. (68) - Rio de Janeiro, 1975.

14.

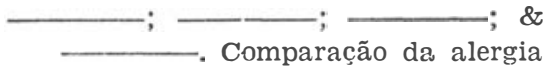
tuberculínica induzida por três tipos de vacina (em impressão).

15. MATOS, Adalgisa Vieira; e col. Participação da esfermagem na implantação do BCG intradérmico no
Brasil. Rev. Div. Nac. Tuberc. Rio de Janeiro (70): 185-192, 1974.

16. MEDICAL RESFARCH COUNCIL BCG and vole bacillus vaccines in the prevention of tuberculosis in adolescence and erly adult life. In. British Medical Journal. London, 1 (13): 937-978, april, 1963.

17. NUTELS, Noel \& MIRANDA, José Antonio Nunes de. Viragem tuberculínica em grupos indígenas vacinados com BCG intradérmico. Rev. Serv. Nac. Tuberc. Rio de Janeiro, 13 (51): 255-282, julho/setembro, 1969.

18. REVISÃO crítica das pesquisas sobre vacinação com o .BCG oral. Rev. Serv. Nac. Tuberc. Rio de Janeiro, 12 (47): 273-88, 1968.

19. ROCHA, Eloadir Pereira da - Vacinação BCG intradérmica e sua aplicação no Estado da Guanabara. Rev. Méd. do Est. da Guanab. Rio de Janeiro, 36 (2) : 157-169, 1969.

20. —— Vacinação intradérmica e sua aplicação no Estado da Guanabara. Rev. Serv. Nac. Taberc. Rio de Janeiro, 14 (54): 137-47, abril/junho, 1970.

21. RSCHKE, Maria Alice C. Técnicas de Avaliacão. Seminário de Didática Aplicada ao Ensino Superior. 14-18 de abril de 1975 (mimeografado).

22. SANTOS NEVES, Jayme dos. Estudn comparativo das vacinas E.CG intradérmicas brasileiras, líquida $\mathrm{e}$ liofilizada. Rio de Janeiro 1974. (Não publicada).

23. TOMAN, Kurt. Conhecimento atual sobre imunização contra a tuberculose (Present knowledge of immunization against tuberculosis, Rev. Div. Nac. Tuberc. Rio de Janeiro, 17 (68): 539-62, out/dez, 1973. 


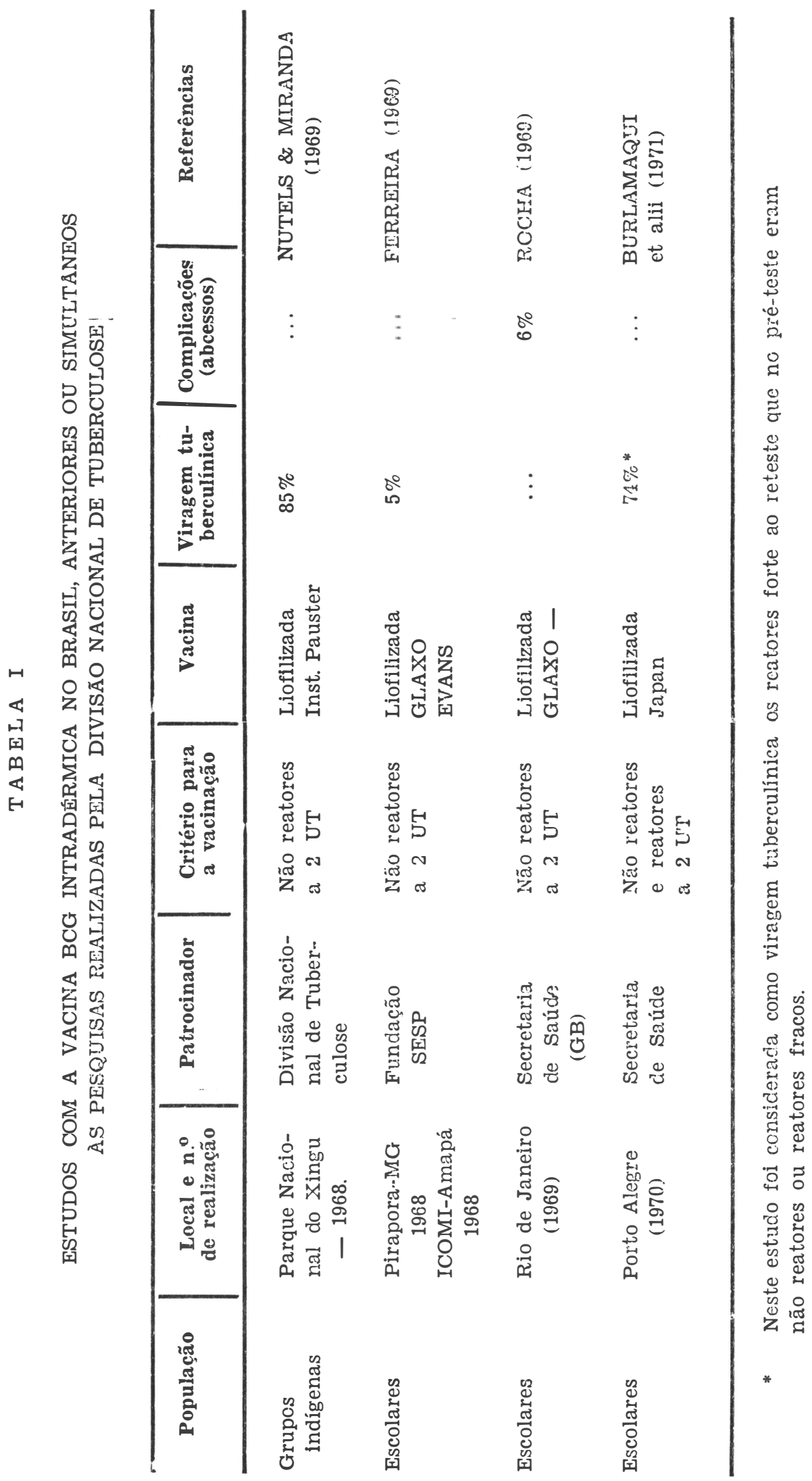




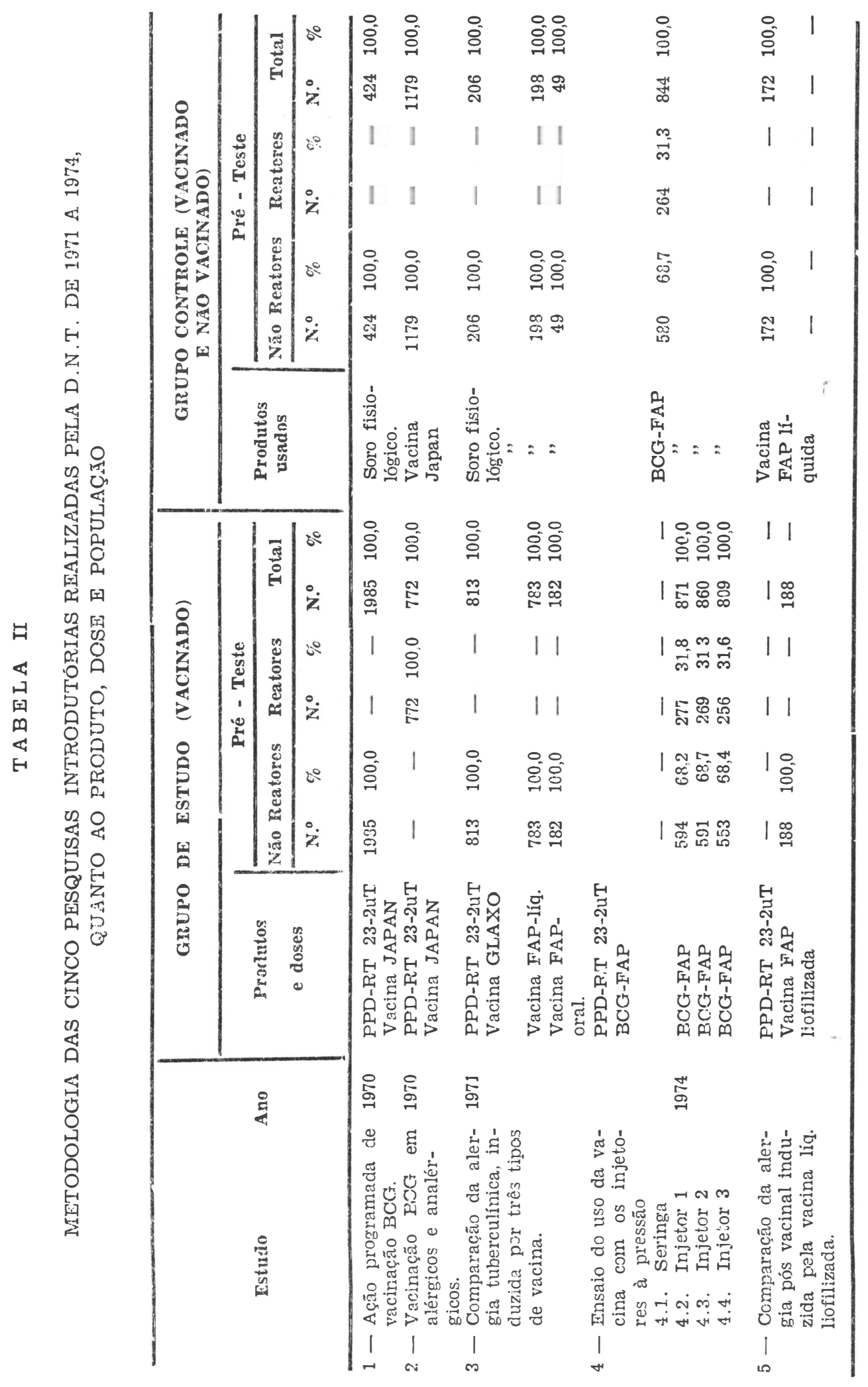




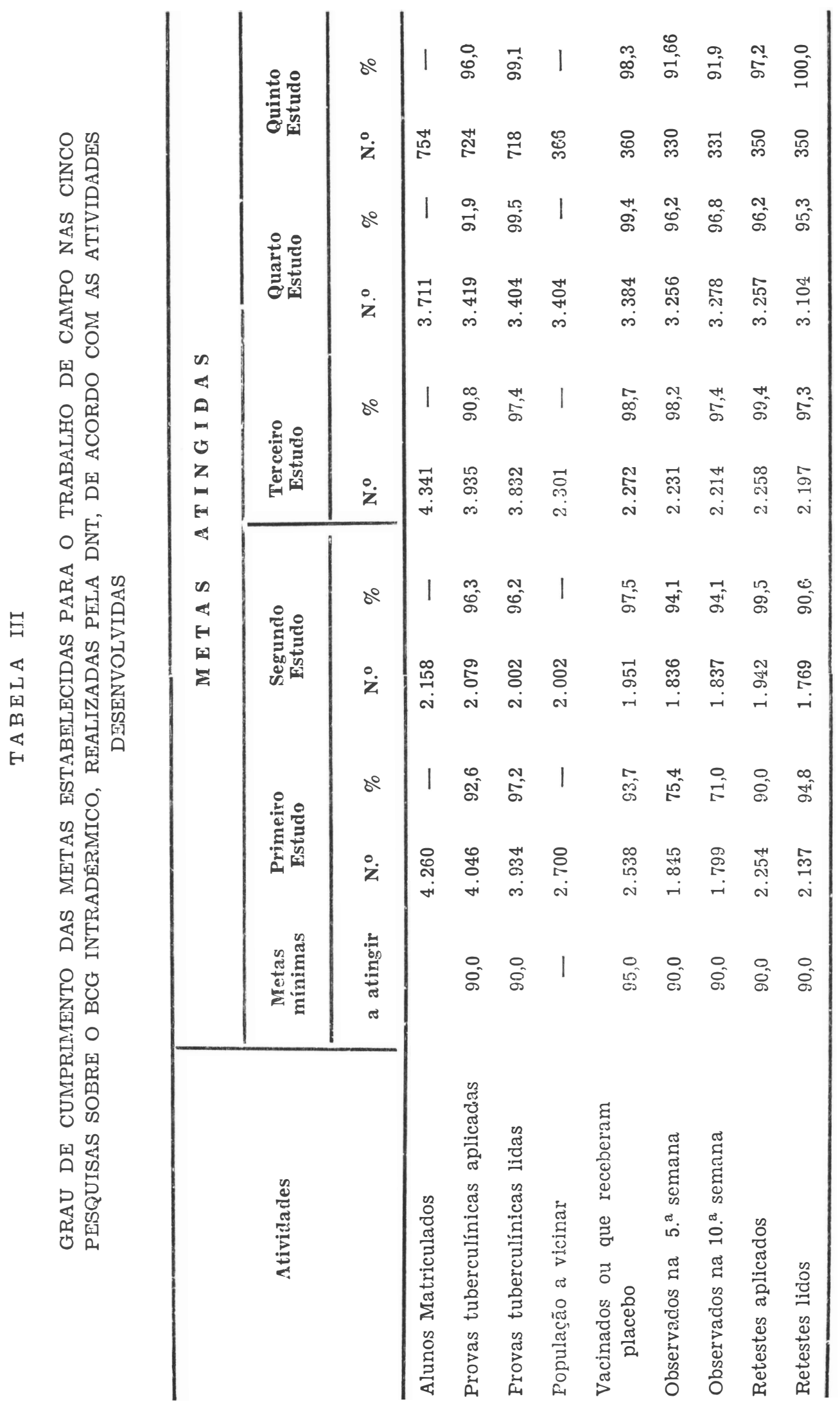




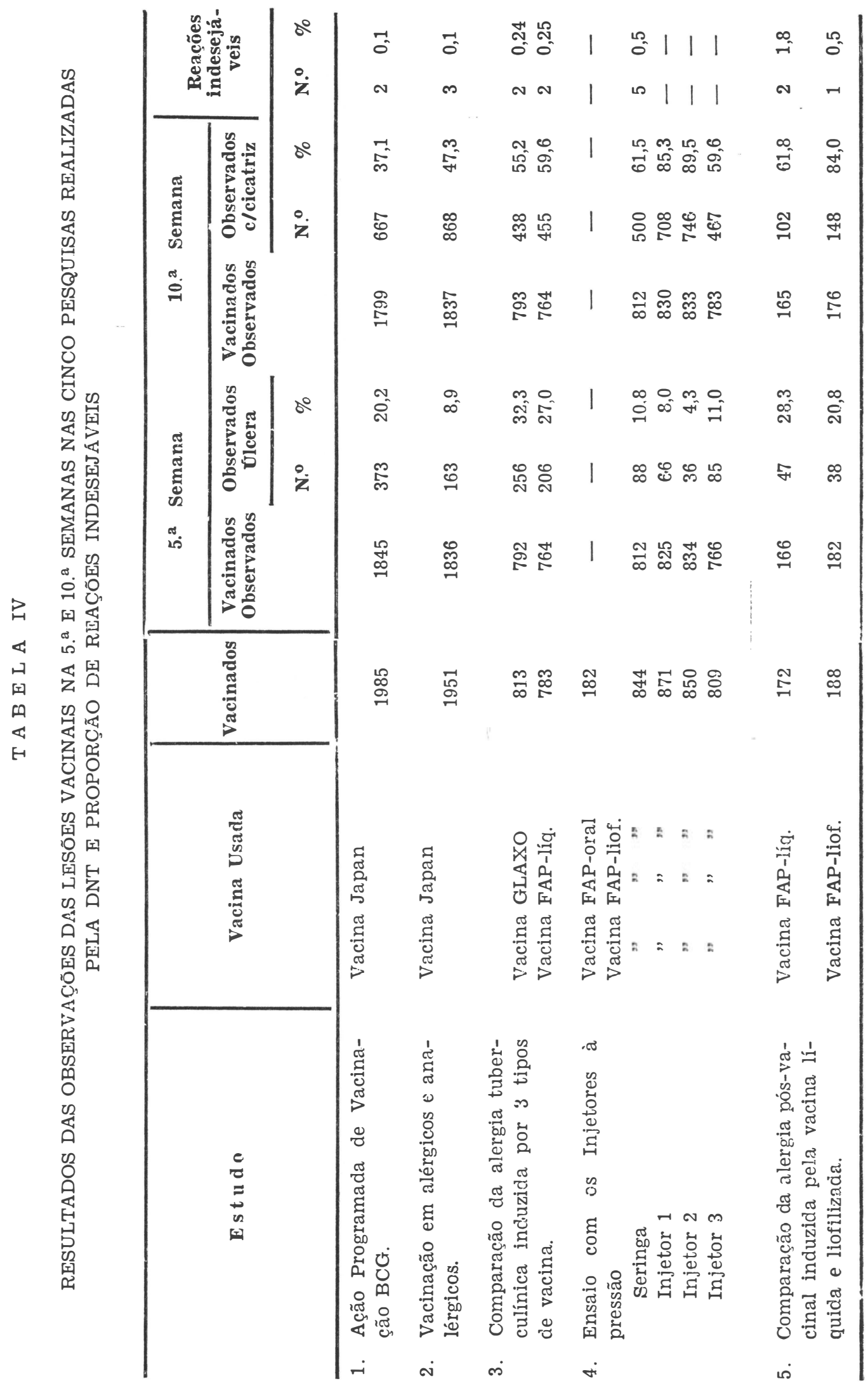




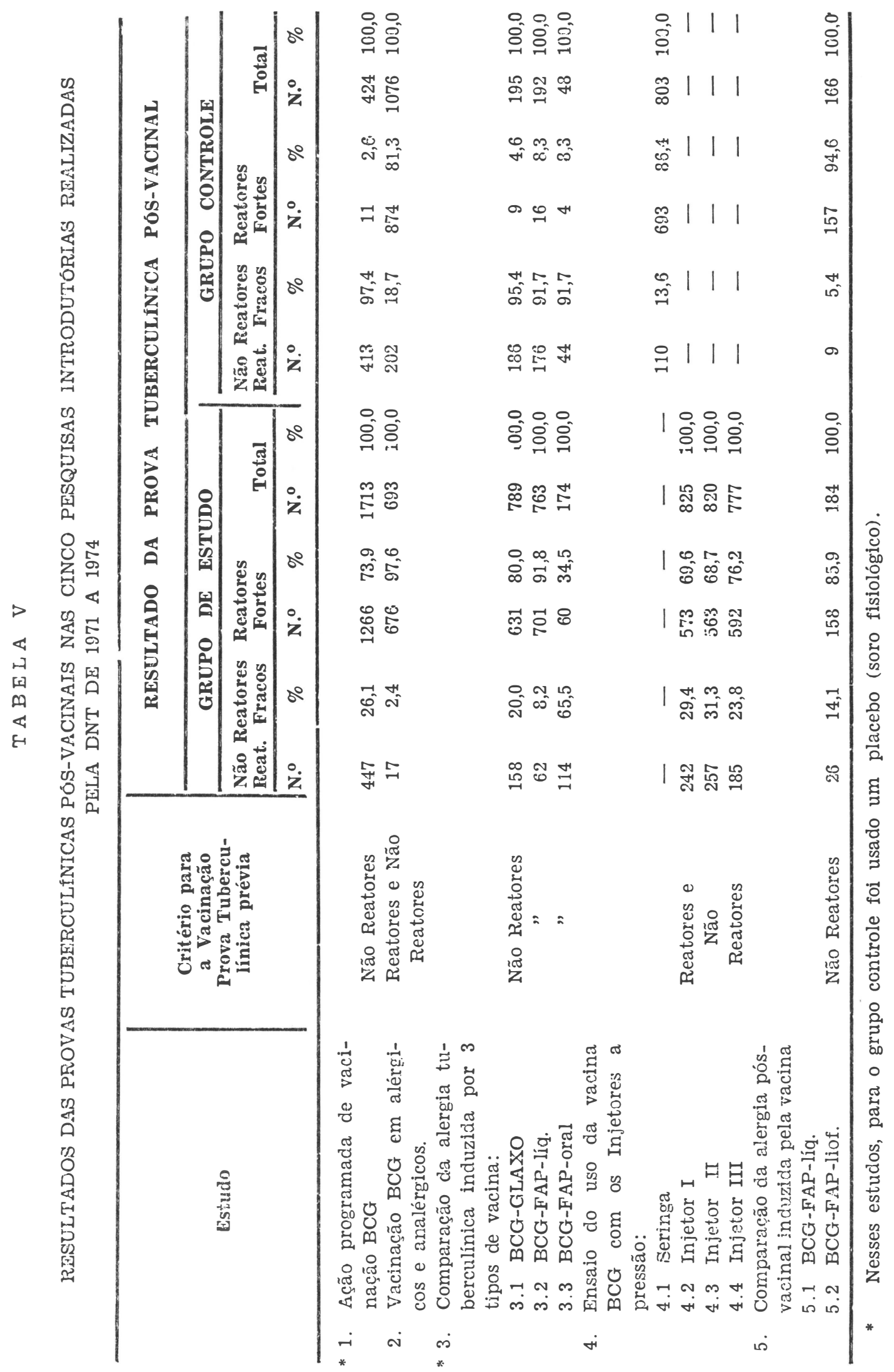




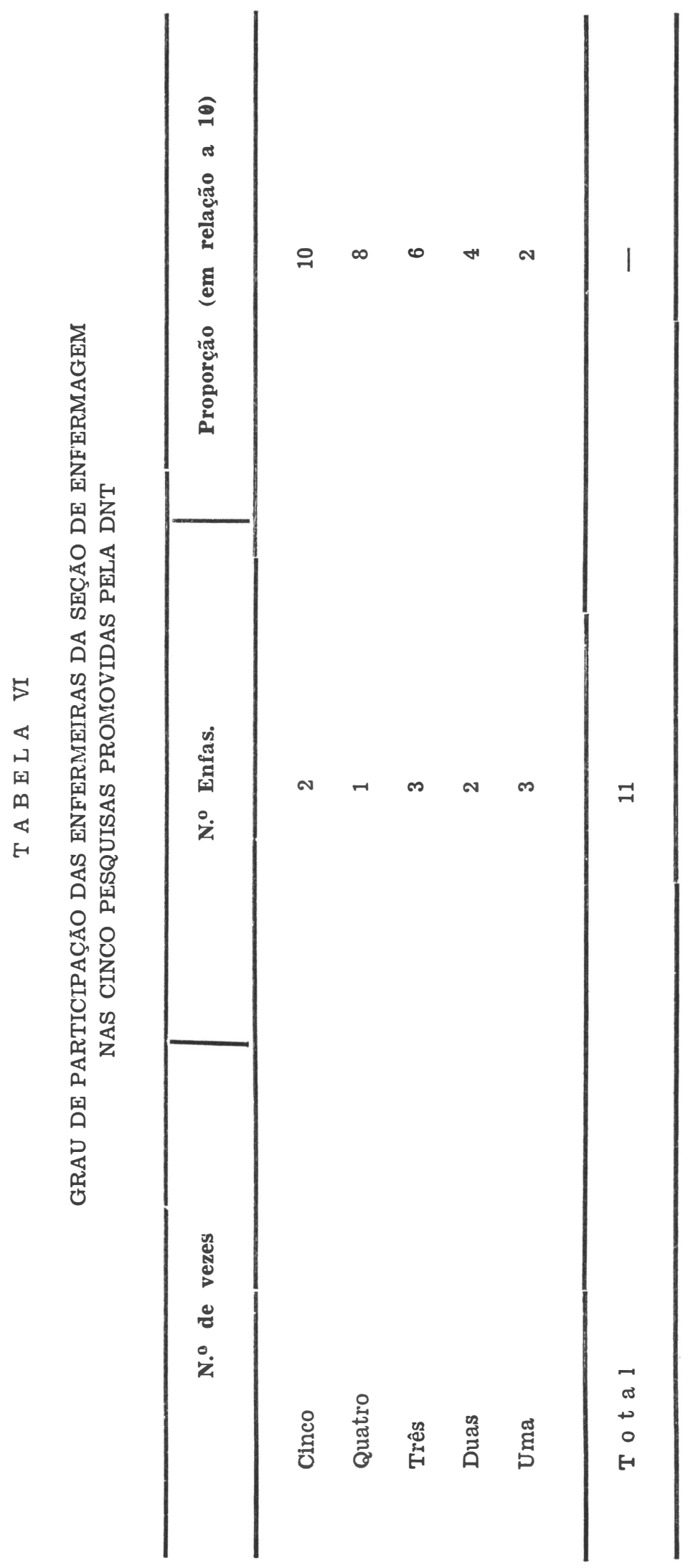




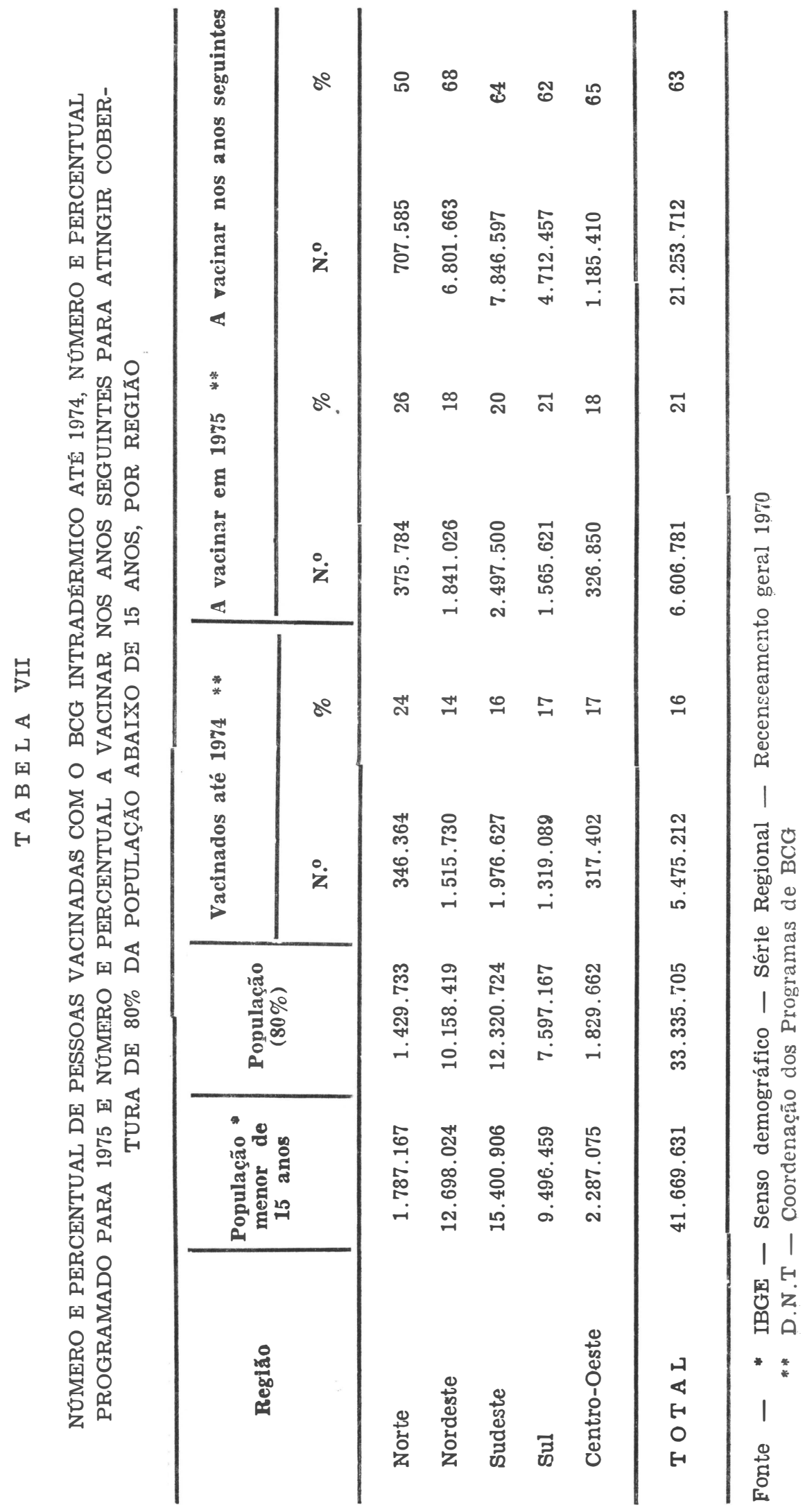




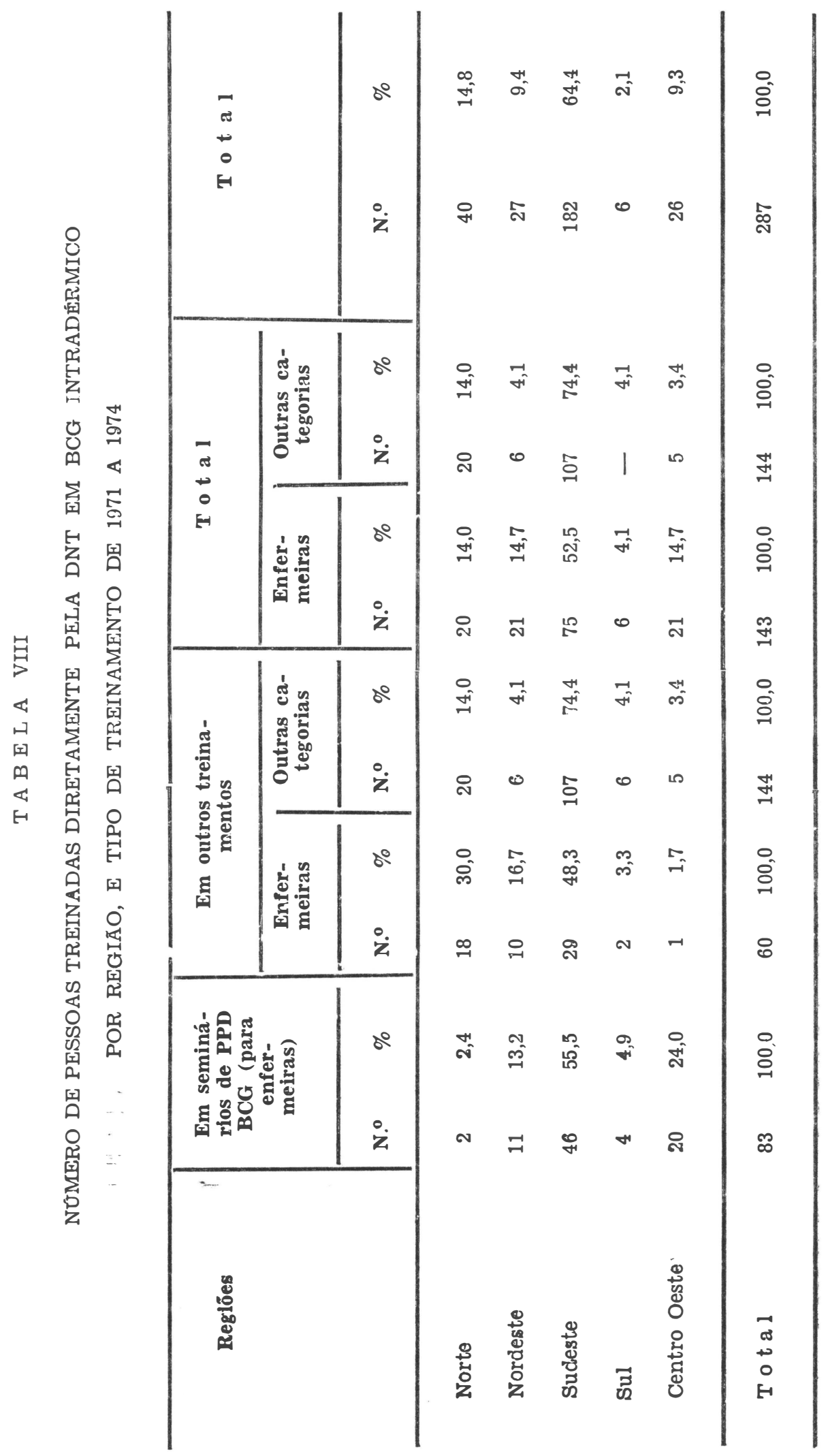

